\title{
Numerical Analysis of Thermal and Moisture Bridges in Insulation Filled Masonry Walls and Corner Joints
}

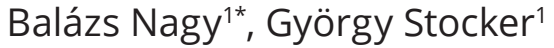 \\ 1 Department of Construction Materials and Technologies, \\ Faculty of Civil Engineering, \\ Budapest University of Technology and Economics \\ H-1111 Budapest, Műegyetem rkp. 3. K.I.85, Hungary \\ *Corresponding author, e-mail: nagy.balazs@epito.bme.hu
}

Received: 13 December 2018, Accepted: 14 February 2019, Published online: 03 April 2019

\begin{abstract}
In recent years, thermal insulation filled masonry blocks have become widespread in Central-Europe. These blocks can satisfy thermal performance requirements without the need of additional insulation. However, these requirements in the building regulations only consider thermal, but neglect moisture aspects. This paper presents a comparative analysis of steady-state numerical conjugated heat- and moisture transport FEM simulations of masonry walls. The hygrothermal material properties of the insulation filled masonry blocks were measured in laboratory. In the paper, besides a wall section, a wall corner joint is presented, both modeled in 2D from complex building elements, such as insulation filled blocks, and were tested using different fillers (aerogel, expanded perlite, expanded polystyrene, mineral wool and PUR foam), respectively. Monthly variation of the fillers' thermal conductivity, thermal and moisture transmittance and effective water vapor diffusion resistance of the walls, as well as linear thermal and moisture transmittance of the wall corner joints were examined in details. A comparison between detailed and simplified modeling were also carried out. The evaluation of the results shows that there are noticeable differences in trends between thermal and moisture transmittances, latter show significantly greater variation and depends mainly on the hygrothermal behavior of the filler. Based on effective water vapor resistance factors, we showed that assuming the same vapor transmission properties for all type of filled masonry blocks is a mistake.
\end{abstract}

\section{Keywords}

masonry, heat and moisture transport, thermal conductivity, thermal bridge, moisture bridge

\section{Introduction}

Due to building energy performance requirements [1] building constructions developed significantly in the past few years. Material producers started to develop new products to prepare for even stricter requirements in the near future [2], when nearly-zero energy buildings (NZEB) will be mandatory to be built. To achieve significant reduction in the heat loss of buildings, demand has increased for thermal insulation layers and the development of new building technology solutions in particular. Masonry producers created thermal insulation filled blocks, shown by Fig. 1, to achieve low thermal transmittance without the need for applying additional insulation. In recent years, researchers investigated the thermal behavior of differently shaped filled masonry blocks with perlite [3-5], phase change materials [6], mineral wool and polyurethane [7], expanded polystyrene $[8,9]$, aerogel [10] and their comparisons [11-13].
In this research, walls and wall corner joints made out of masonry blocks filled with 5 different thermal insulation fillers were examined using numerical modeling supported by laboratory measurement of the material properties. The main goal was to compare different steady-state numerical simulation approaches in terms of the filled masonry blocks, and answer how surface temperatures, thermal and moisture transmittances, linear thermal and moisture transmittances and thermal conductivity of filler materials change, if we consider hygrothermal (conjugated heat and moisture transport, HAM) aspects too. Effective water vapor diffusion resistance factors of the wall constructions were also determined and compared. Although steady-state numerical simulations neglect the effects of heat and moisture capacity and cannot take dynamic climatic data into account, but they are widely used in building energy calculations 
(e.g. energy performance certification) to obtain thermal transmittances, or to evaluate and design the reduction of the effect of thermal bridges in building constructions.

\section{Materials}

\subsection{Geometry of the thermal insulation filled blocks}

Scaled 2D geometry models of the evaluated building constructions are shown in Fig. 2. The multidimensional geometry models were constructed according to the technical guidance of the industry leading masonry block producer in Hungary [14]. As observable in Fig. 2, horizontal section of a masonry wall was modelled.

The wall constructions modeled is comprised of $24.9 \mathrm{~cm} \times 24.8 \mathrm{~cm} \times 44 \mathrm{~cm}$ thermal insulation filled masonry blocks. In the model, one full size block is accompanied with two half blocks on either side for better numerical results. The internal structures of the blocks were modeled according to the most common design of such blocks. The horizontal dryfix layer between the blocks was not taken into consideration in the $2 \mathrm{D}$ model, while vertical joints were connected to each other with tongue and groove connection. $1.5 \mathrm{~cm}$ thick gypsum plaster was applied to the internal and $2 \mathrm{~cm}$ thick layer of insulating plaster was on the external surface. In the corner detail presented in Fig. 3, the corner element is constructed by using a $2 / 3$ and a $1 / 2$ cut masonry block mortared together.

\subsection{Material properties}

In the numerical simulations, the hollow masonry blocks were filled with 5 different thermal insulations: aerogel blanket (AG), polyurethane foam (PUR), mineral wool (MW), expanded polystyrene (EPS) and expanded perlite (EXP). The basic material properties of the thermal insulations, as well as of those of fired clay (FC), internal plaster (IP) and external plaster (EP) are listed in Table 1, and were measured in laboratory. The thermal conductivity is measured according to MSZ EN 12667 [15] and determined using $\lambda_{10, d r y}[\mathrm{~W} /(\mathrm{m} \cdot \mathrm{K})]$ with the addition of the $f_{T}$ temperature and $f_{\psi}$ moisture dependent conversion factors from MSZ EN ISO 10456 [16]. Water vapor resistance factors are measured according to MSZ EN ISO 12572 [17] for

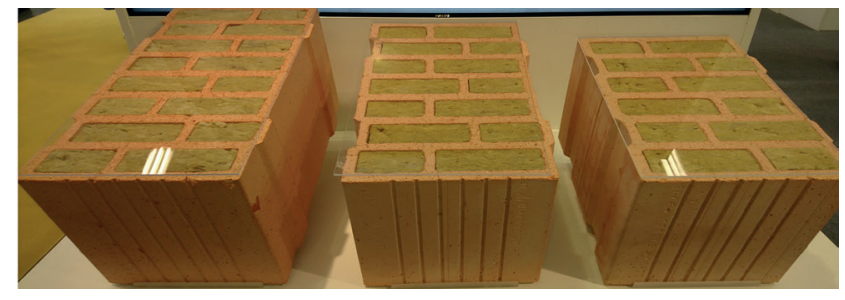

Fig. 1 Mineral wool filled masonry blocks

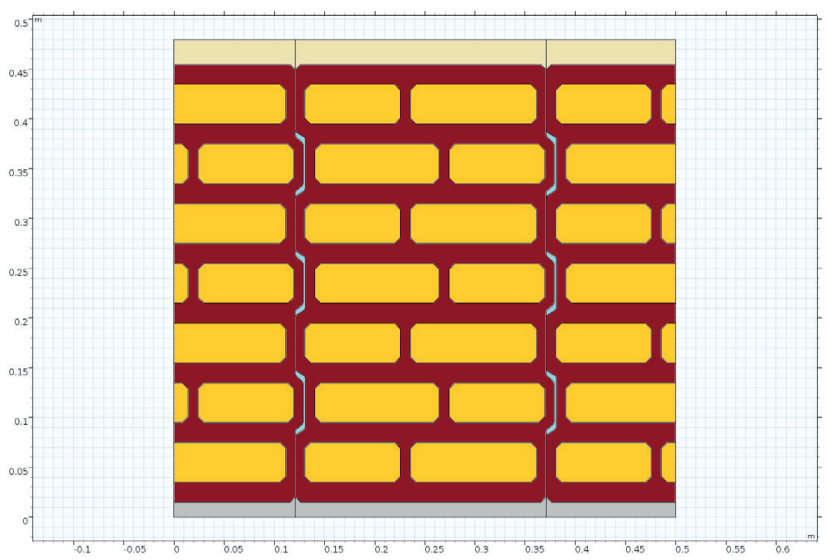

Fig. 2 Model of thermal insulation filled masonry wall

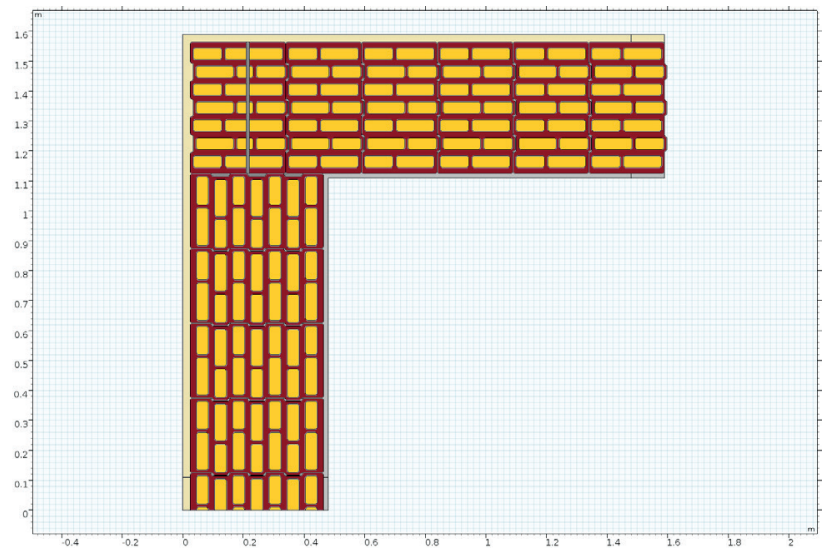

Fig. 3 Model of masonry wall corner joint

dry and wet conditions: $\mu_{d r y / w e t}[1]$. The hygroscopic sorption isotherms were measured according to MSZ EN ISO 12571 [18] using salt solutions, and the moisture storage curves are presented in Fig. 4 and Fig. 5. It is observable that aerogel blanket and expanded polystyrene are the most hygroscopic materials from the thermal insulation fillers, while mineral wool and expanded perlite does not take up much moisture

Table 1 Measured hygrothermal material properties

\begin{tabular}{|c|c|c|c|c|c|c|c|c|}
\hline Material & $\mathrm{AG}$ & PUR & MW & EPS & EXP & $\mathrm{FC}$ & IP & EP \\
\hline Thermal conductivity, $\lambda_{10, d r y}[\mathrm{~W} /(\mathrm{m} \cdot \mathrm{K})]$ & 0.012 & 0.024 & 0.031 & 0.037 & 0.05 & 0.35 & 0.4 & 0.09 \\
\hline Temperature conversion factor, $f_{T}[1 / \mathrm{K}]$ & 0.0015 & 0.0055 & 0.0045 & 0.0035 & 0.0035 & 0.001 & 0.001 & 0.001 \\
\hline Moisture conversion factor, $f_{\psi}\left[\mathrm{m}^{3} / \mathrm{m}^{3}\right]$ & 3 & 6 & 4 & 4 & 3 & 10 & 3 & 8 \\
\hline Water vapor resistance factor, $\mu_{d r y / \text { wet }}[1]$ & 4.5 & $80 / 70$ & 1.3 & $70 / 30$ & 2 & $15 / 10$ & 8.1 & 8.3 \\
\hline
\end{tabular}



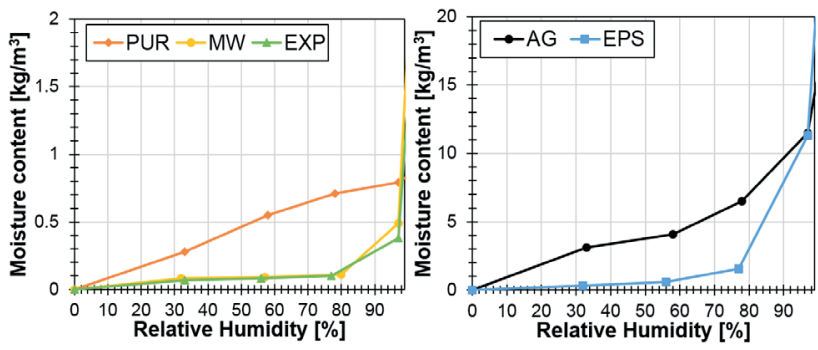

Fig. 4 Moisture storage curves of thermal insulation materials, left: PUR, MW and EXP, right: AG and EPS

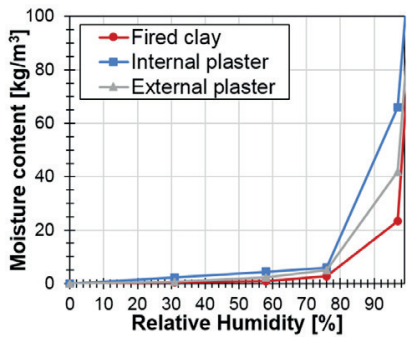

Fig. 5 Moisture storage curves of fired clay, internal and external plaster

when stored under $90 \%$ relative humidity. The plasters and fired clay are visualized in different graphs because of their significantly higher moisture storage capacity comparing to the thermal insulations.

The measured material properties were compared to similar materials from the WUFI database [19], the differences and trends of the hygrothermal material properties were not prominent, therefore we considered the measurements to be valid.

\section{Methods}

\subsection{Conjugated heat and moisture transport}

In the research, monthly based steady-state conjugated heat and moisture transfer (HAM) simulations were carried out based on [20-23]. The partial differential equation (PDE) of steady-state heat transfer is shown in Eq. (1), in which the first member represents heat fluxes from heat conduction and the second part shows heat fluxes from evaporation fluxes. In Eq. (1), $\nabla$ is nabla vectorial differential operator, $\mathbf{q}$ is heat flux $\left[\mathrm{W} / \mathrm{m}^{2}\right], \lambda_{\text {eff }}=\lambda_{10, d r y} \cdot e^{f_{T}}\left(T_{2}-10^{\circ} C\right) \cdot e^{f_{\psi}}\left(u_{2}\right)$ is the temperature and volumetric moisture content dependent effective thermal conductivity $[\mathrm{W} /(\mathrm{m} \cdot \mathrm{K})], T$ is tempe- rature $[\mathrm{K}], L_{v}$ is latent heat of evaporation of water $[\mathrm{J} / \mathrm{kg}]$, $\delta_{p}=\delta_{a} / \mu$ is vapor permeability $[\mathrm{kg} /(\mathrm{m} \cdot \mathrm{s} \cdot \mathrm{Pa})]$, in which $\delta_{a}$ is the vapor permeability of still air depending on air temperature and $\mu$ is the vapor resistance factor [1], $\varphi$ is relative humidity [1] and $p_{\text {sat }}$ is the saturation pressure of water vapor $[\mathrm{Pa}]$, depending on the temperature:

$\nabla \mathbf{q}=\nabla\left[\lambda_{e f f} \nabla T+L_{v} \delta_{p} \nabla\left(\varphi p_{\text {sat }}(T)\right)\right]=0$.

The PDE of steady-state moisture transfer is defined in Eq. (2), in which the first member of the equation represents the liquid transport of the moisture fluxes, while the second is responsible for moisture fluxes from vapor transport:

$\nabla \mathbf{g}=\nabla\left[\xi D_{w} \nabla \varphi+\delta_{p} \nabla\left(\varphi p_{s a t}(T)\right)\right]=0$.

In Eq. (2), $\mathbf{g}$ is moisture flux $\left[\mathrm{kg} /\left(\mathrm{m}^{2} \cdot \mathrm{s}\right)\right], \xi$ is differential moisture capacity $\left[\mathrm{kg} / \mathrm{m}^{3}\right]$ according to the hygroscopic sorption isotherms of the materials and $D_{w}$ liquid transport coefficient $\left[\mathrm{m}^{2} / \mathrm{s}\right]$. Steady-state simulation was chosen instead of performing time dependent hourly based simulations, since the main objective of the research was to compare thermal and moisture transmittances and linear thermal- and moisture transmittances of the building constructions considering monthly design conditions to each other, and also to evaluate the effect of neglecting the moisture transfer. For evaluating linear thermal transmittances of building construction, usually thermal only approach is considered nowadays $[24,25]$, however adding moisture transport will increase the heat losses of components. The partial differential equations shown in Eq. (1) and (2) were implemented in COMSOL Multiphysics FEM software [26], where parametric sweep was used for the monthly different boundary conditions and material sweep to study the different insulation fillers.

\subsection{Boundary conditions}

Due to chosen monthly method, only temperature and relative humidity were taken into account as the basis of the boundary conditions. Monthly averaged external data sets of Budapest were obtained from Meteonorm 7 [27] and shown in Table 2. Since there is no $80 \%$ or higher external relative humidity in the average monthly values, liquid transport was neglected $\left(D_{w}=0\right)$.

Table 2 Monthly average temperature and relative humidity data of Budapest, Hungary

\begin{tabular}{lccccccccccccc}
\hline Month & I. & II. & III. & IV. & V. & VI. & VII. & VIII. & IX. & X. & XI. & XII. \\
\hline External temperature $\left[{ }^{\circ} \mathrm{C}\right]$ & 0.9 & 2.8 & 7.0 & 13.3 & 18.4 & 21.4 & 23.1 & 22.8 & 17.4 & 12.5 & 7.2 & 1.7 & 0.5 \\
External relative humidity [1] & 0.73 & 0.68 & 0.61 & 0.52 & 0.53 & 0.54 & 0.54 & 0.54 & 0.62 & 0.69 & 0.73 & 0.74 \\
Internal temperature $\left[{ }^{\circ} \mathrm{C}\right]$ & 20.0 & 20.0 & 20.0 & 21.7 & 24.2 & 25.0 & 25.0 & 25.0 & 23.7 & 21.3 & 20.0 & 20.0 \\
Internal relative humidity [1] & 0.41 & 0.43 & 0.47 & 0.53 & 0.58 & 0.60 & 0.60 & 0.60 & 0.57 & 0.53 & 0.47 & 0.42 \\
\hline
\end{tabular}


Internal conditions of air, and equivalent vapour diffusion thicknesses of the boundary layers were set according to MSZ EN 15026 [23] for normal occupancy. Surface heat transfer coefficients were set based on MSZ EN ISO 6946 [28]. The heat transfer coefficient were $h_{s i}=7.69 \mathrm{~W} /\left(\mathrm{m}^{2} \cdot \mathrm{K}\right)$ for internal and $h_{s e}=25 \mathrm{~W} /\left(\mathrm{m}^{2} \cdot \mathrm{K}\right)$ for external surfaces, the equivalent vapor diffusion thickness of boundary layer was set to $s_{d, s i}=0.008 \mathrm{~m}$ on the internal and $s_{d, s e}=0.0023 \mathrm{~m}$ on the external surface. In cases, where average temperature and wind speed dependent boundary conditions were used to compare its effects on the heat and moisture fluxes, the heat fluxes on internal surfaces are represented in Eq. (3) and on external surfaces in Eq. (4), while the moisture fluxes on internal surfaces are shown by Eq. (5), and on external surfaces by Eq. (6):

$$
\begin{aligned}
& -\mathbf{n} \cdot \mathbf{q}=d_{z}\left(h_{c i}+\varepsilon \cdot 4 \cdot \sigma \cdot T_{m, i}^{3}\right), \\
& -\mathbf{n} \cdot \mathbf{q}=d_{z}\left(h_{c e}+\varepsilon \cdot 4 \cdot \sigma \cdot T_{m, e}^{3}\right), \\
& -\mathbf{n} \cdot \mathbf{g}=d_{z}\left[\beta_{i}\left(\varphi_{i} \cdot p_{s a t}\left(T_{i}\right)-\varphi_{s i} \cdot p_{s a t}\left(T_{s i}\right)\right)\right], \\
& -\mathbf{n} \cdot \mathbf{g}=d_{z}\left[\beta_{e}\left(\varphi_{e} \cdot p_{s a t}\left(T_{e}\right)-\varphi_{s i} \cdot p_{s a t}\left(T_{s e}\right)\right)\right] .
\end{aligned}
$$

In Eq. (3), $d_{z}$ represents the height of the examined building element $(1 \mathrm{~m}), h_{c i}$ is the internal convective surface heat transfer coefficient $\left(2.5 \mathrm{~W} /\left(\mathrm{m}^{2} \cdot \mathrm{K}\right)\right), \varepsilon$ is the longwave emissivity of the surface $(0.9), \sigma$ is the Stefan-Boltzmann constant $\left(5.67 \cdot 10^{-8} \mathrm{~W} /\left(\mathrm{m}^{2} \cdot \mathrm{K}^{4}\right)\right)$ and $T_{m i}$ is the mean thermodynamic temperature of the internal surface and its surroundings in Kelvin. In Eq. (4), $h_{c e}=4+4 \cdot v$, where $v$ is the wind speed in $[\mathrm{m} / \mathrm{s}]$ and $T_{m e}$ is the mean thermodynamic temperature of the external surface and its surroundings in [K]. In Eq. (5), $\beta_{i}=\delta_{a} / S_{d, s i}$ is the moisture transfer coefficient on the surfaces in $\left[\mathrm{kg} /\left(\mathrm{m}^{2} \cdot \mathrm{s} \cdot \mathrm{Pa}\right)\right], \varphi_{i}, \varphi_{s i}$ and $T_{i}, T_{s i}$ are the internal air and surface relative humidity [1] and internal air and surface temperatures [K]. In Eq. (6), $\beta_{i}=\delta_{a} / S_{d, s e}$, where $S_{d, s e}=1 /(67+90 \cdot v)[\mathrm{m}]$ and $\varphi_{e}, \varphi_{s e}$ and $T_{e}, T_{s e}$ are the external air and surface relative humidity [1] and external air and surface temperatures $[\mathrm{K}]$.

\subsection{Linear thermal and moisture transmittances}

Thermal transmittance $\left(U\right.$ value $\left.\left[\mathrm{W} /\left(\mathrm{m}^{2} \cdot \mathrm{K}\right)\right]\right)$ shows how much heat (Joules of energy within 1 second, $Q[\mathrm{~W}=\mathrm{J} / \mathrm{s}]$ ) could flow through an $A=1 \mathrm{~m}^{2}$ of internal surface of the building element in case of $\Delta T=1 \mathrm{~K}$ temperature difference as defined in Eq. (7):

$U=Q /(A \cdot \Delta T)$.
The additional heat loss due to thermal bridges of building structures are characterized by calculating a linear thermal transmittance $(\psi$ value $[\mathrm{W} /(\mathrm{m} \cdot \mathrm{K})]$ ), which shows how much heat could flow additionally due to multidimensional heat flow comparing to surface thermal transmittance. Based on the MSZ EN ISO 10211 [29], $\psi$ value can be calculated from the thermal coupling coefficient $L_{2 D}$ $[\mathrm{W} /(\mathrm{m} \cdot \mathrm{K})]$ of the building element separating two spaces (e.g. internal and external space), the $U_{i}$ thermal transmittance and the $l_{i}$ internal length of the joining building elements according to the Eq. (8):

$\psi=L_{2 D}-\sum_{j} U_{j} \cdot l_{j}$.

The thermal coupling coefficient in Eq. (8) can be defined as the ratio of the internal surface heat flow $(Q[\mathrm{~W}])$ and the temperature difference multiplied by the internal length, presented in Eq. (9):

$L_{2 D}=Q /(l \cdot \Delta T)$.

To characterize the moisture behavior of a building element, we can introduce and define the $M\left[\mathrm{~kg} /\left(\mathrm{m}^{2} \cdot \mathrm{s} \cdot \mathrm{Pa}\right)\right]$ moisture transmittance value. $M$ value can be calculated according to Eq. (10), as the ratio of $G[\mathrm{~kg} / \mathrm{s}]$ internal surface moisture flow through $1 \mathrm{~m}^{2}$ of internal surface of the building element at $\Delta p$ water vapor pressure difference:

$M=G /(A \cdot \Delta p)$.

If a building element can be simplified to one layer and considered homogeneous, and if it does not consist of any capillary active material, then moisture transmittance, presented in Eq. (10) is equal to the vapor permeability multiplied by $1 \mathrm{~m}$ length. From this, effective water vapor diffusion resistance factor can be easily defined, as dividing vapor permeability of air by the building element specific value. Calculation of the moisture transmittance of complex, inhomogeneous building elements could only have carried out effectively by using HAM simulation. For characterization of moisture bridges, introduction of the linear moisture transmittance is necessary, which is designated as Greek letter, and can be determined in a similar way to the linear thermal transmittance, see Eq. (11). $v$ value $[\mathrm{kg} /(\mathrm{m} \cdot \mathrm{s} \cdot \mathrm{Pa})]$ shows how many kilograms of additional moisture can flow through one running meter of a construction joint within a second comparing to the moisture transmittance of the connecting building elements measured at the internal length:

$v=G /(l \cdot \Delta p)-\Sigma_{j} M_{j} \cdot l_{j}$. 
Based on Eq. (10) and Eq. (11), it can be seen that for the calculation of the moisture transmittances, $G$ moisture flow on the internal surface of the building structure, caused by the $\Delta p$ water vapor pressure difference, has to be determined. The water vapor pressure difference can be calculated by using Eq. (12) from the $T$ air temperature $[\mathrm{K}]$ and $\varphi$ relative humidity of the separated spaces (e.g. internal and external space):

$\Delta p=\varphi_{i} \cdot p_{s a t}\left(T_{i}\right)-\varphi_{e} \cdot p_{s a t}\left(T_{e}\right)$.

Water vapor pressure of saturated air can be obtained by using MSZ EN ISO 13788 [30]. During the investigation, the effects of solar radiation and driving rain were neglected, because these are highly dynamic parameters and monthly averages do not express their behavior.

\section{Results and discussion}

\subsection{Simplified and detailed geometry modelling}

Usually, masonry constructions in energy performance calculations are considered as a simplified, single and homogeneous layer. Technical datasheets of masonry blocks give only effective thermal conductivity and an approximated water vapor diffusion resistance factor for the wall. The latter one is usually $\mu_{d r y / w e t}=10 / 5$ from MSZ EN 1745 [31] standard for any fired clay masonry product.
Datasheets do not give any additional and/or detailed information, such as the temperature or moisture conversion coefficients, sorption isotherm, or liquid transport coefficient, that are necessary to perform a conjugated heat and moisture transport simulations. The problems with all of these simplification are indicated in Fig. 6. Average results are similar to the simplified models, but local minimums and maximums differ, and there is great difference of the distribution of heat and moisture fluxes within the model. Using simplified models can hide design problems.

\subsection{Monthly variation of the thermal conductivity of insulating materials in wall sections}

Effective thermal conductivity of every domain and material were retrieved from each numerical simulation. The most interesting results among them were for the insulation fillers. The monthly value of the effective thermal conductivity heavily depends on the hygrothermal properties of the filler material as shown by Fig 7. and Fig. 8. In the figures, the behavior of mineral wool (MW) and expanded polystyrene (EPS) fillers are shown.

Increasing temperature and relative humidity increase the $\lambda_{\text {eff }}$ of the materials, but the rate of increase is different depending on the material. In Fig. 7, it is clearly visible, that the outermost layer of the MW filler performs the best

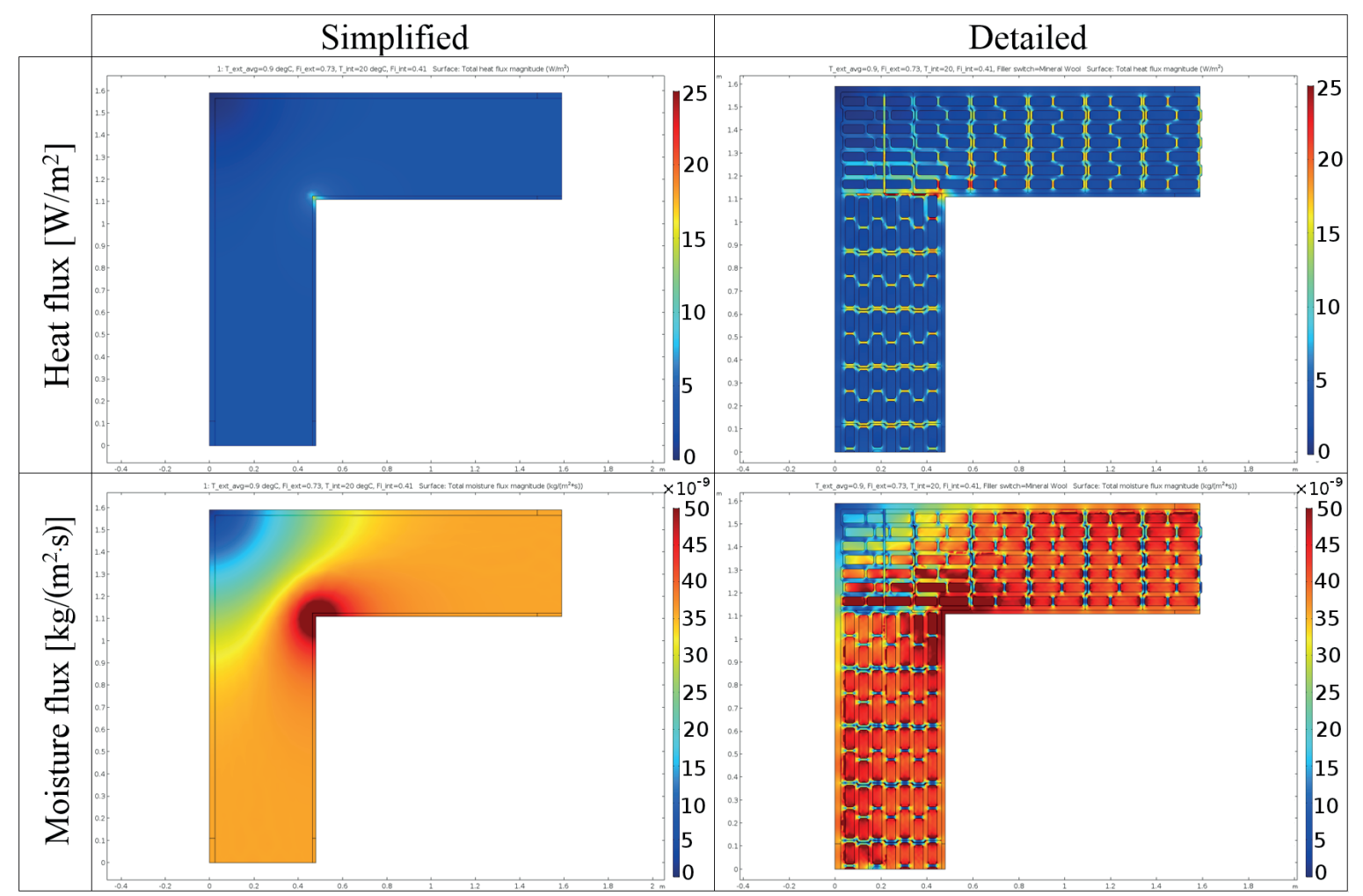

Fig. 6 Differences in heat and moisture flux between simplified and detailed geometry modelling of a wall corner in January 


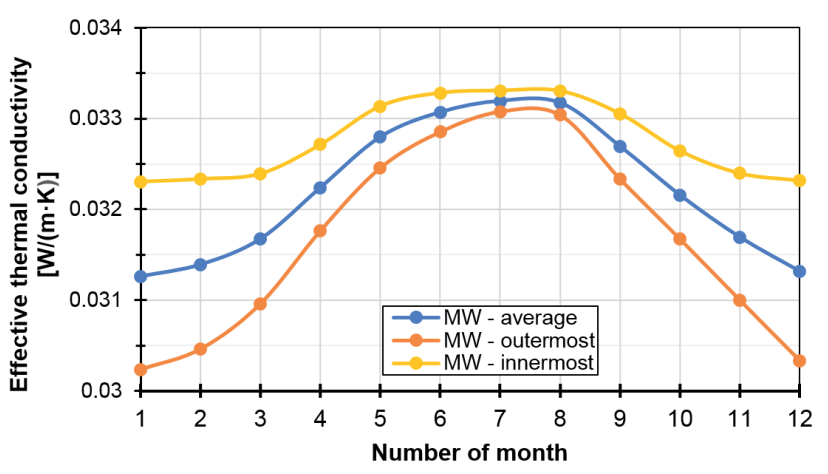

Fig. 7 Effective thermal conductivity of MW fillers in walls

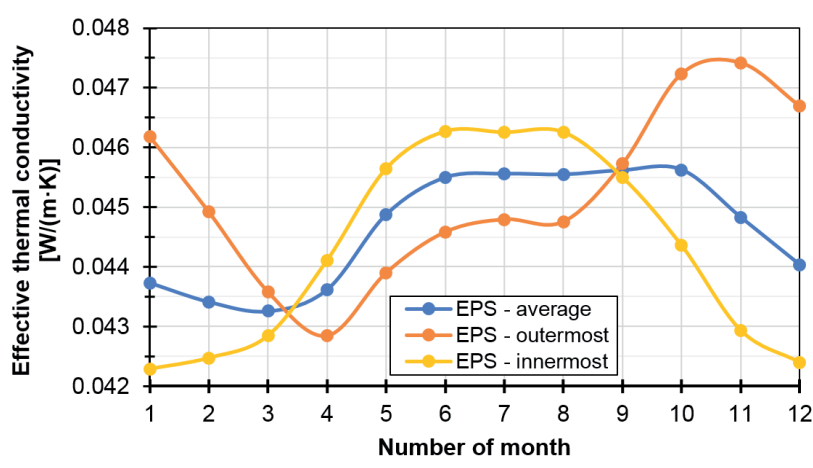

Fig. 8 Effective thermal conductivity of EPS fillers in walls

Table 3 Increase of average $\lambda_{\text {eff }}$ of the insulation fillers in the masonry blocks compared to their $\lambda_{10, d r y}$ values

\begin{tabular}{lccccc}
\hline Filler material & AG & PUR & MW & EPS & EXP \\
\hline Heating season [\%] & 10.99 & 10.60 & 1.50 & 18.53 & 1.12 \\
Summer [\%] & 12.64 & 118.19 & 6.92 & 23.06 & 5.29 \\
Yearly average [\%] & 11.76 & 14.04 & 3.94 & 20.63 & 2.99 \\
\hline
\end{tabular}

and the innermost layer has the highest thermal conductivity during the year, since MW does not take up much moisture due to its hydrophobic nature. However, in Fig. 9. it is visible, that e.g. in January, the relative humidity in the outermost layer of the insulation can exceed the relative humidity of external air (0.73), because fired clay layer blocks the moisture flow, which increases the relative humidity in the MW. On one hand, this moisture block can result in moisture damages in the external one-third of the blocks and should be analyzed in details by using dynamic simulations in a next research. On the other hand, while the relative humidity is high, the moisture storage capacity of the MW is low, therefore its moisture content remains low and the moisture transfer does not affect greatly the thermal conductivity. In contrast, temperature distribution in the section shows, that there are lower temperature values in the external region, therefore thermal conductivity of MW closer to the external side is lower. EXP shows the same trend as MW (Table 3). PUR behaves similarly to the above-mentioned fillers, the increase of its $\lambda_{\text {eff }}$ is greater due to is higher moisture capacity. Analyzing the results of EPS, we see that outermost layer has higher $\lambda_{\text {eff }}$ from September till March. This can be explained by the fact, that EPS is more sensitive to high relative humidity, that occurs in the external side of the blocks. AG showed the same trends on the monthly values as EPS. Differences for the heating season (November to March), summer (June to August) and yearly averages are summarized in Table 3. Increased $\lambda_{\text {eff }}$ leads to increased thermal transmittance, which results in more heat losses in the heating season.

\subsection{Thermal and moisture bridges}

Heat and moisture fluxes of MW and EPS filled masonry wall corners are presented in Fig. 10. Heat flux magnitudes are higher in the fired clay internal structures parallel to heat flow direction in both cases, while the increase of moisture flux magnitude depends heavily on the moisture transfer properties of the filler. In the case of EPS filler, the maximum values of the moisture flux are observable in the fired clay internal structures and in the tongue and groove connections, while in the case of MW filler, the moisture easily flows through the filler, therefore higher fluxes are visible in the filler and in the internal corner. In multidimensional problems, heat and moisture flows always find the shortest possible way through materials with lower thermal or moisture resistance and cause thermal or moisture bridges within the building constructions.

\subsection{Thermal transmittance of walls and wall corners}

Fig. 11. shows the average $U$ values of walls and $\psi$ values of the wall corner joints in case of different fillers are shown by Fig. 12. It is clearly visible that $U$ value of walls increase in summer months due to the rising temperature.

In summer there are also lower temperature differences between internal and external spaces. The $U$ values show great differences depending on the insulation filler. Walls made of EXP filled masonry blocks have $57 \%$ higher thermal transmittance in January compared to AG filler. In summer, the difference between MW and EPS filled blocks reduces. Linear thermal transmittance shows the additional heat loss occurs in the wall corner comparing to the adjoining walls. $\psi$ values show only slight differences, each month the results do not differ more than 0.02 $\mathrm{W} /(\mathrm{m} \cdot \mathrm{K})$, the highest difference occurs between $\mathrm{AG}$ and EXP filled blocks it is $18.8 \%$. 


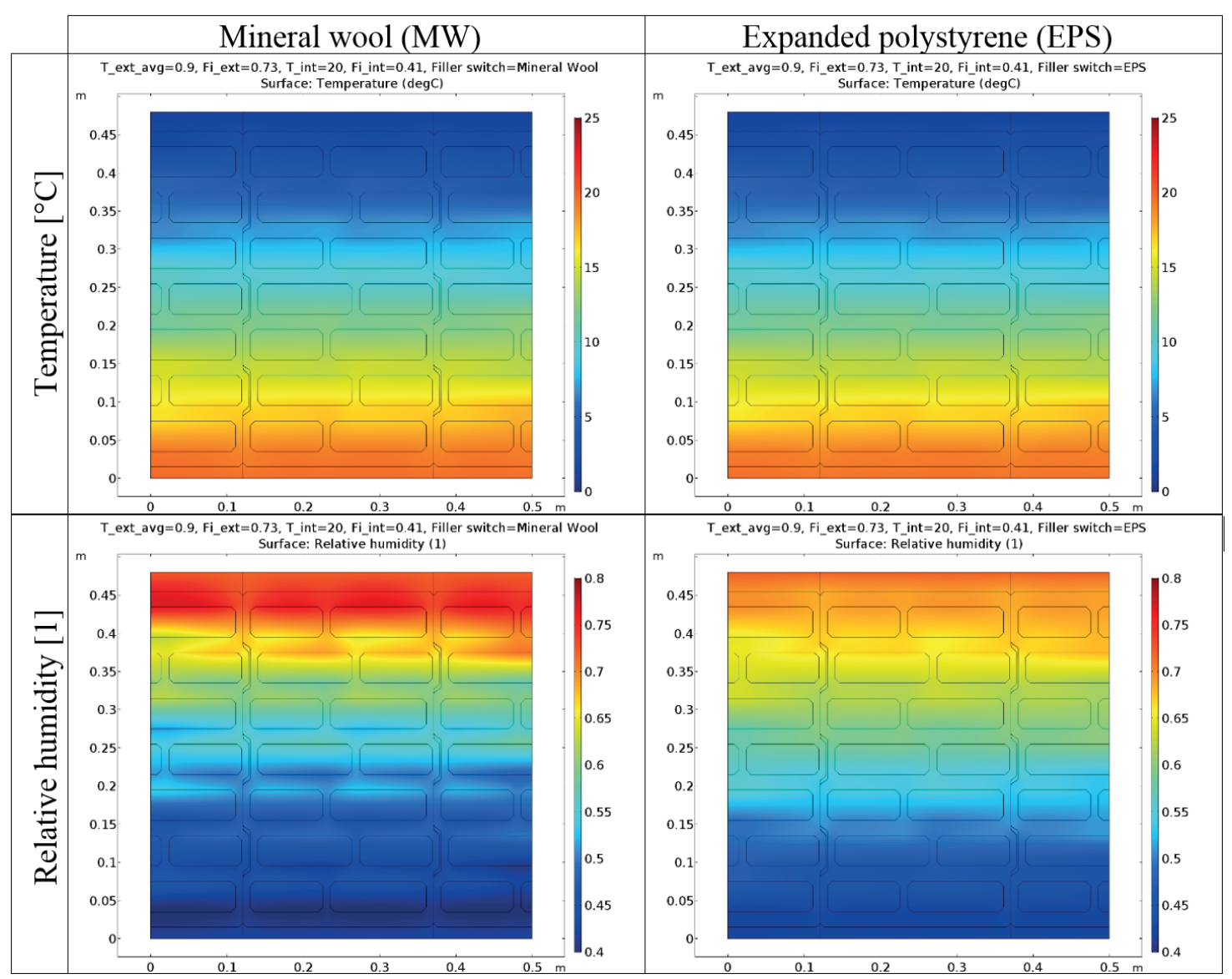

Fig. 9 Temperature and relative humidity distribution in walls made out of MW7 and EPS filled masonry blocks in January

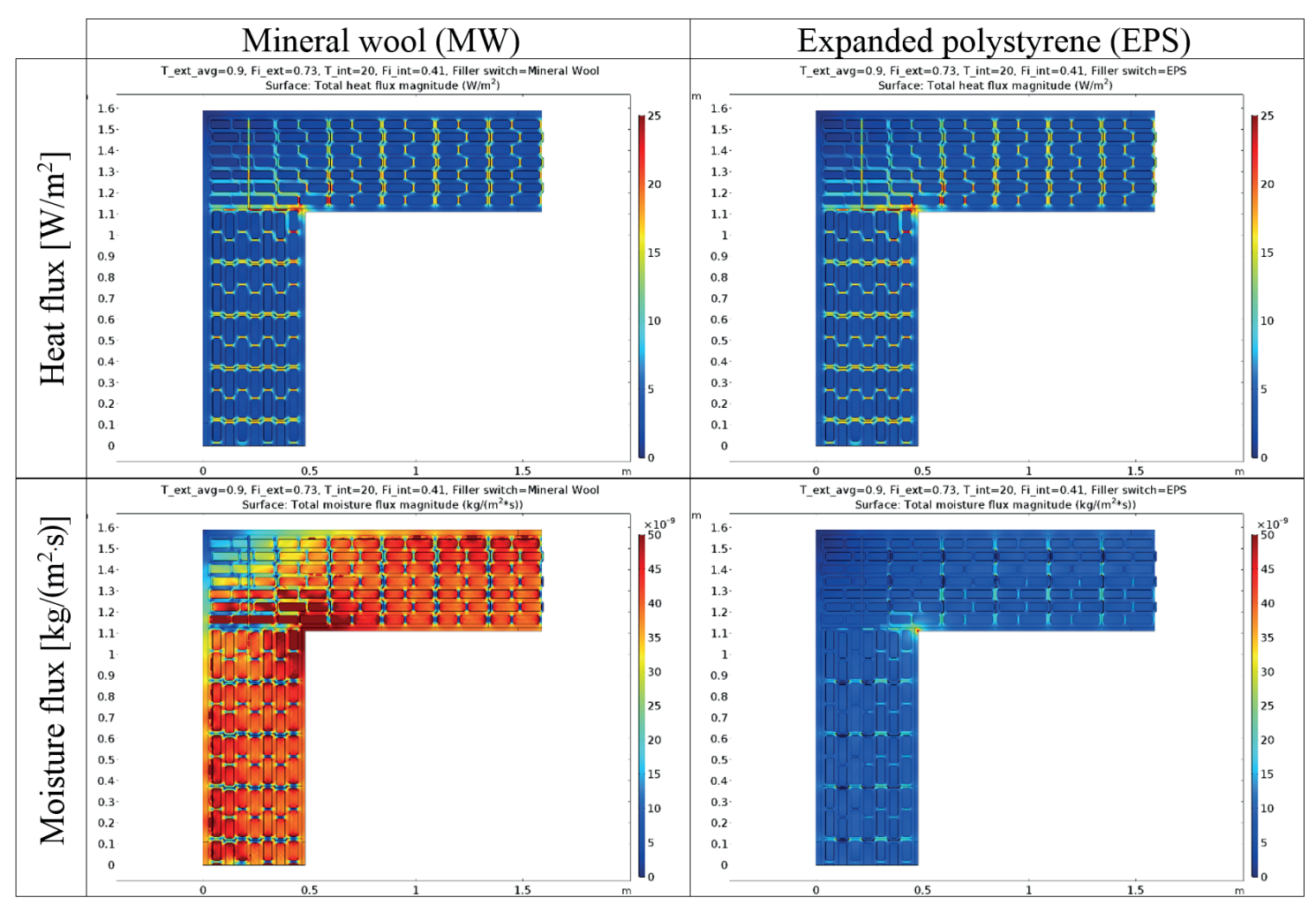

Fig. 10 Heat and moisture flux distribution in wall corner joints made of MW and EPS filled masonry blocks in January 


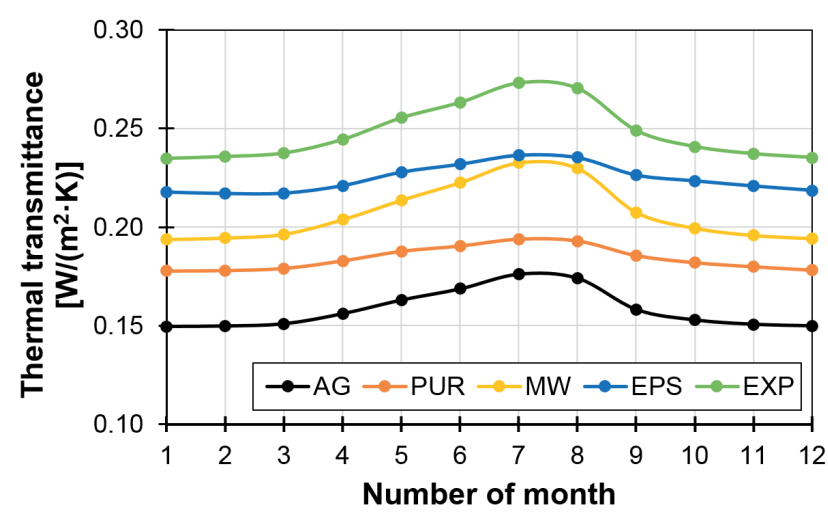

Fig. 11 Monthly thermal transmittance of walls

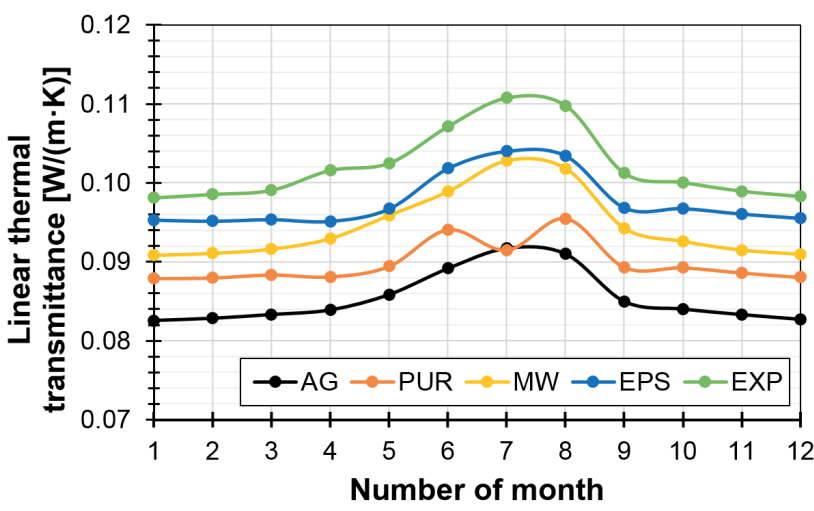

Fig. 12 Monthly linear thermal transmittance of wall corners

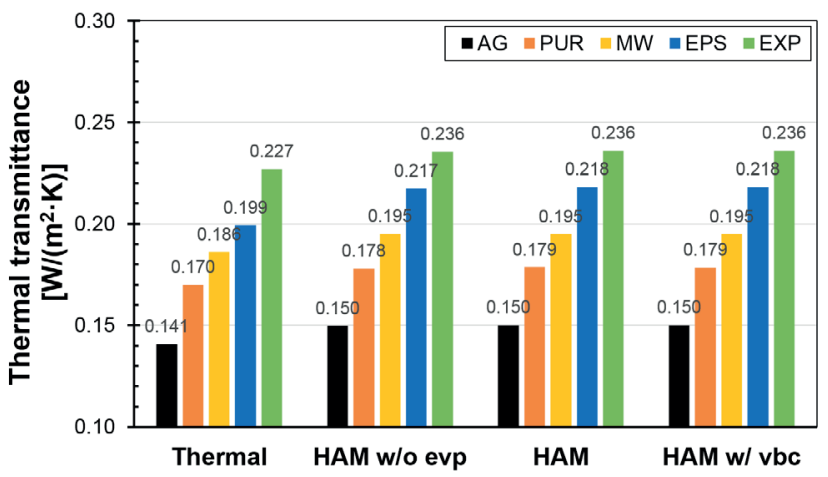

Fig. 13 Heating season averaged $U$ values of thermal, HAM w/o evp, $\mathrm{HAM}$ and $\mathrm{HAM} \mathrm{w} / \mathrm{vbc}$ simulations

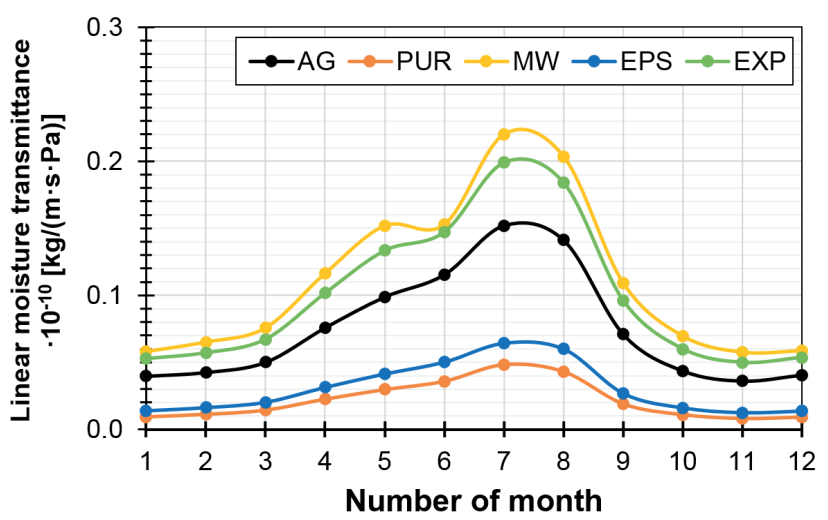

Fig. 14 Monthly moisture transmittance of walls
Additionally, besides the HAM simulations, three different set of simulations were performed with different settings. The first case was a thermal simulation (Thermal), where only heat transfer was considered with temperature dependent thermal conductivities. In the second case, we neglected the heat fluxes coming from evaporation fluxes (HAM w/o evp) and in the third case, temperature, relative humidity and wind-dependent, monthly variable boundary conditions were used according to Eq. (3-6) instead of simplified boundary conditions (HAM w/vbc). It is observable in Fig. 13, which presents averaged values over the heating season, that there is significant, $3.9 \%$ to $8.7 \%$ negative difference between thermal and hygrothermal simulations, which means that considering only thermal approach is underestimating the thermal transmittance of the building constructions. However, there are only slight differences visible if evaporation fluxes are neglected, and using variable boundary conditions in the heating season do not show any differences in the $U$ value results.

\subsection{Moisture transmittance of walls and wall corners}

Monthly variation of the moisture transmittances is shown by Fig. 14. It is visible that $M$ values show greater variation and differences than $U$ values, and the order from lower to higher transmittances by filler materials changed.

The values occurring in case of filler materials with low water vapor resistance factor (e.g. AG, MW and EXP) are considerably higher than the ones with high resistance against vapor (PUR and EPS). Walls constructed out of MW filled masonry blocks let 5.6 times more moisture through, than PUR filled bricks in January, and 4.5 times more in July. The performance trend of the masonry walls in terms of moisture transmittance shows inverse relationship with the water vapor resistance factors of the filler materials; the filler material is substantially more dominant, than the fired clay of the construction.

After calculating the effective water vapor resistance factor of the walls shown in Fig. 15, it is visible that in cases of PUR and EPS fillers, $\mu_{\text {eff }}$ are significantly higher in the heating season compared to other, moisture permeable fillers. We can conclude that in case of thermal insulation filled masonry blocks, if the vapor permeability of the filler material is higher than the fired clay shell (i.e. AG, MW and EXP), then using the values of fired clay could be acceptable. However, if the permeability of the filler is lower, therefore resistance is higher (i.e. PUR and EPS), using the values of fired clay (10/5) as substitution according to the standard [31] leads to miscalculations in the heating season and this practice should be avoided. 


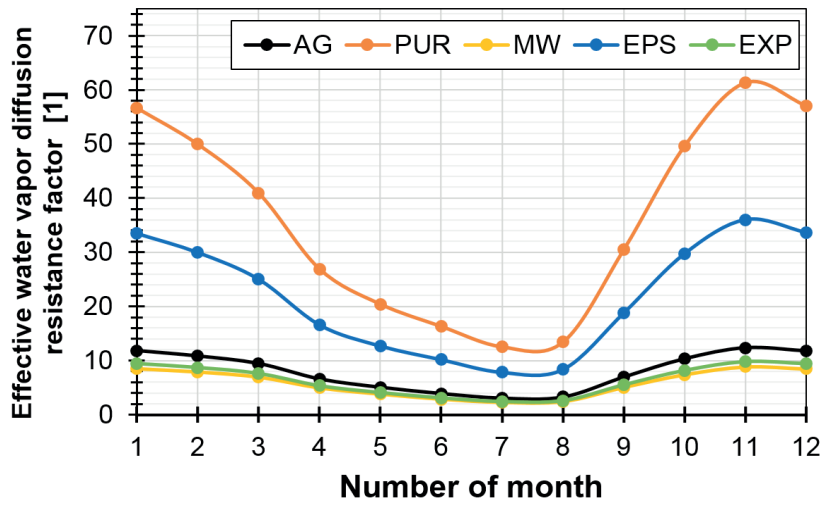

Fig. 15 Monthly linear moisture transmittance of wall corners

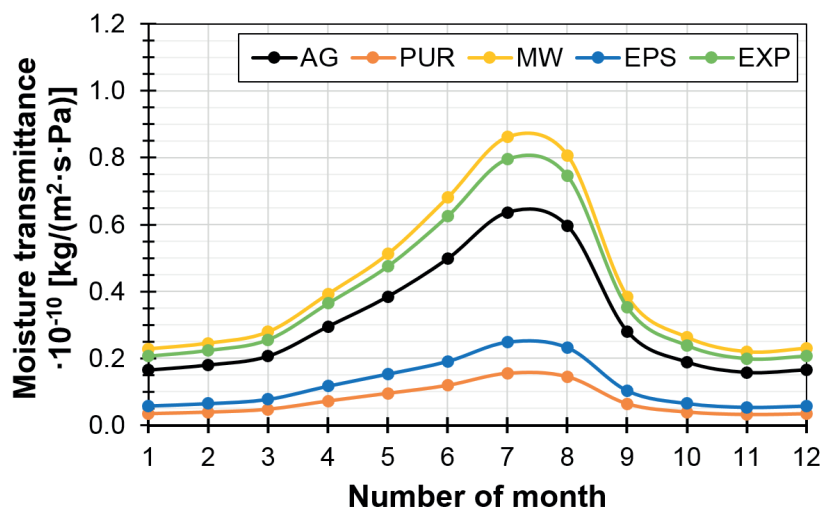

Fig. 16 Monthly effective water vapor diffusion resistance factor of walls

Evaluating the linear moisture transmittances shown in Fig. 16. the trend of the filled masonry walls remained the same. The differences between the fillers only slightly reduced, there is 5.2 times difference in January between the $v$ values of PUR and MW filled constructions, and there is 3.5 times difference in July.

\section{Conclusions}

In this paper, the effects of thermal and moisture bridges of walls and wall corners made of 5 different thermal insulation filled masonry blocks were analyzed by 2D steadystate numerical modelling. We showed, that in case of the examined structures, heat and moisture fluxes should be analyzed with the detailed geometry of blocks within the walls and wall corner joints.

\section{References}

[1] Arcipowska, A., Anagnostopoulos, F., Mariottini, F., Kunkel, S. "Energy Performance Certificates Across The EU: A Mapping of National Approaches", BPIE, Brussels, Belgium, 2014.

[2] Hermelink, A., Schimschar, S., Boermans, T., Pagliano, L., Zangheri, P. et al. "Towards nearly zero-energy buildings", Ecofys Germany GmbH, Köln, Germany, Final Report, 2012.
We evaluated the monthly variation of the thermal conductivity of insulation fillers within the masonry blocks, and found two groups of differently behaving fillers. PUR, MW and EXP showed similar trends, and AG and EPS also behaved similarly in the examined months. These trends show good agreement with the moisture storage curves of the materials. In case of lower moisture capacity, the $\mu_{\text {eff }}$ of the outermost layer of filler insulation, has smaller increase in the heating season.

Thermal and moisture bridges of the constructions were also evaluated, and we observed greater differences in the moisture transmittances of the structures than in the thermal transmittances. Thermal transmittances of walls constructed of $44 \mathrm{~cm}$ thick insulation filled masonry blocks obtained by steady-state conjugated heat and moisture transport modelling varied between $0.14 \mathrm{~W} /\left(\mathrm{m}^{2} \cdot \mathrm{K}\right)$ and $0.23 \mathrm{~W} /\left(\mathrm{m}^{2} \cdot \mathrm{K}\right)$ in the heating season, depending mostly on the filler hygrothermal properties.

In this paper, we introduced the linear moisture transmittance which could be a good parameter to help designers plan appropriate constructions not only according to thermal aspects, but also considering the effect of moisture transport. Using the moisture transmittance, we showed that there are significant differences between walls and wall corner joints depending on the insulation filler, and moisture transmittance show greater variation than thermal transmittance. We also concluded that the effective water vapor diffusion resistance factors of the walls are significantly different, when the filler material has higher water vapor resistance factor than the fired clay shell (i.e. PUR and EPS). Therefore, assuming the same vapor transmission properties for all type of filled masonry blocks is a mistake commonly made by masonry manufacturers in technical datasheets.

\section{Acknowledgement}

Project FK 128663 has been implemented with the support provided from the National Research, Development and Innovation Fund of Hungary, financed under the FK_18 funding scheme. Support of grant BME FIKP-VÍZ by EMMI is kindly acknowledged.

[3] Topçu, I. B., Iş̧ıdağ, B. "Manufacture of high heat conductivity resistant clay bricks containing perlite", Building and Environment, 42(10), pp. 3540-3546, 2007.

https://doi.org/10.1016/j.buildenv.2006.10.016

[4] Zukowski, M., Haese, G. "Experimental and numerical investigation of a hollow brick filled with perlite insulation", Energy and Buildings, 42(9), pp. 1402-1408, 2010. https://doi.org/10.1016/j.enbuild.2010.03.009 
[5] Arici, M., Yılmaz, B., Karabay, H. "Investigation of Heat Insulation Performance of Hollow Clay Bricks Filled with Perlite", ACTA Phyica Polonica A, 130(1), pp. 266-268, 2016.

https:/doi.org/10.12693/APhysPolA.130.266

[6] Principi, P., Fioretti, R. "Thermal analysis of the application of PCM and low emissivity coating in hollow bricks", Energy and Building, 51, pp. 131-142, 2012.

https://doi.org/10.1016/j.enbuild.2012.04.022

[7] Kočí, J., Maděra, J., Jerman, M., Černý, R. "Effect of cavity filler on the effective thermal conductivity of hollow bricks: a computational analysis based on accurate input data", In: Proceedings of the 2nd Central European Symposium on Building Physics, Vienna, Austria, 2013, pp. 635-639.

[8] Pavlík, Z., Jerman, M., Trník, A., Kočí, V., Černý, R. "Effective thermal conductivity of hollow bricks with cavities filled by air and expanded polystyrene", Journal of Building Physics, 37(4) pp. 436-448, 2014.

https://doi.org/10.1177/1744259113499214

[9] Li, J., Meng, X., Gao, Y., Mao, W., Luo, T., Zhang, L. "Effect of the insulation materials filling on the thermal performance of sintered hollow bricks", Case Studies in Thermal Engineering, 11, pp. 62-70, 2018. https://doi.org/10.1016/j.csite.2017.12.007

[10] Wernery, J., Ben-Ishai, A., Binder, B., Brunner, S. "Aerobrick - An aerogel-filled insulated brick", Energy Procedia, 134, pp. 490-498, 2017.

https://doi.org/10.1016/j.egypro.2017.09.607

[11] Nagy, B., Orosz, M. "Optimized Thermal Performance Design of Filled Ceramic Masonry Blocks", Applied Mechanics and Materials, 797, pp. 174-181, 2015.

https://doi.org/10.4028/www.scientific.net/AMM.797.174

[12] Nagy, B., Tóth, E. "Hygrothermal behaviour of hollow and filled ceramic masonry blocks", In: International RILEM Conference on Materials, Systems and Structures in Civil Engineering, Lyngby, Denmark, 2016, pp. 279-288.

[13] Nagy, B. "Hygrothermal modelling of masonry blocks filled with thermal insulation", presented at MATBUD'2018 - 8th ScientificTechnical Conference on Material Problems in Civil Engineering, Cracow, Poland, June, 25-27, 2018. https://oi.org/10.1051/matecconf/201816308006

[14] Wienerberger AG. "Wienerberger Technical Manual", [pdf] Wienerberger AG, Budapest, Hungary, [online] Available at: https://wienerberger.hu/downloads/20180226130109/wienerberger-alkalmazástechnikai-és-tervezési-útmutató-2018.pdf [Accessed: 30.11.2018]

[15] MSZ EN 12667:2001 "Thermal performance of building materials and products. Determination of thermal resistance by means of guarded hot plate and heat flow meter methods. Products of high and medium thermal resistance", Hungarian Standards Institute, Budapest, 2001.

[16] MSZ EN ISO 10456:2007 "Building materials and products. Hygrothermal properties. Tabulated design values and procedures for determining declared and design thermal values (ISO 10456:2007)", Hungarian Standards Institute, Budapest, 2007.

[17] MSZ EN ISO 15272:2016 "Hygrothermal performance of building materials and products. Determination of water vapour transmission properties. Cup method (ISO 12572:2016)", Hungarian Standards Institute, Budapest, 2016.
[18] MSZ EN ISO 12571:2013 "Hygrothermal performance of building materials and products. Determination of hygroscopic sorption properties (ISO 12571:2013)", Hungarian Standards Institute, Budapest, 2013.

[19] Fraunhofer IBP, "WUFI PRO 6.3" [computer program] Available at: https://wufi.de/en/2018/04/09/release-wufi-pro-6-2/ [Accessed: 27.03.2019]

[20] Künzel, H. M. "Simultaneous Heat and Moisture Transport in Building Components. One and two-dimensional calculation using simple parameters", 1st ed., Fraunhofer IRB Verlag, Stuttgart, Germany, 1995.

[21] Ponikiewski, T., Steidl, T., Krause, P. "Moisture Transport in Cellular Concrete Walls with the Connector for Thermal Insulation", Periodica Polytechnica Civil Engineering, 62(4), pp. 986-991, 2018. https://doi.org/10.3311/PPci.11618

[22] van Schijndel, A. W. M. "HAM Construction modelling using COMSOL with MatLab Modeling Guide version 1.0", presented at Proceeding of the COMSOL Users Conference, Eindhoven, Netherland, October, 1, 2006.

[23] MSZ EN 15026:2007 "Hygrothermal performance of building components and building elements. Assessment of moisture transfer by numerical simulation", Hungarian Standards Institute, Budapest, 2007.

[24] Bakonyi, D., Dobszay, G. "A proposed methodology for the improvement of the simplified calculation of thermal bridges for well typified facades", Periodica Polytechnica Civil Engineering, 58(4), pp. 309-318, 2014. https://doi.org/10.3311/PPci.7215

[25] Grudzińska, M., Brzyski, P. "The Occurrence of Thermal Bridges in Hemp-Lime Construction Junctions", Periodica Polytechnica Civil Engineering, 2019. https://doi.org/10.3311/PPci.13377

[26] COMSOL, Inc. "Comsol Multiphyics 5.3", [computer progam] Available at: https://www.comsol.com/release/5.3 [Accessed: 27.03.2019]

[27] Meteotest AG "Meteonorm 7.2", [computer program] Available at: https://meteonorm.com/en/download [Accessed: 27.03.2019]

[28] MSZ EN ISO 6946:2017 "Building components and building elements. Thermal resistance and thermal transmittance. Calculation methods (ISO 6946:2017)", Hungarian Standards Institute, Budapest, 2017.

[29] MSZ EN ISO 10211:2017 "Thermal bridges in building construction. Heat flows and surface temperatures. Detailed calculations (ISO 10211:2017)", Hungarian Standards Institute, Budapest, 2017.

[30] MSZ EN ISO 13788:2013 "Hygrothermal performance of building components and building elements. Internal surface temperature to avoid critical surface humidity and interstitial condensation. Calculation methods (ISO 13788:2012)", Hungarian Standards Institute, Budapest, 2013.

[31] MSZ EN 1745:2012 "Masonry and masonry products. Methods for determining thermal properties", Hungarian Standards Institute, Budapest, 2012. 